\title{
SECURE E-VOTING MENGGUNAKAN METODE RSA DAN AUTENTIKASI RFID
}

\author{
Annisaa Sri Indrawanti ${ }^{1)}$, Azmuri Wahyu Azinar ${ }^{2)}$, M. Anang Firdiansyah ${ }^{3)}$ \\ 1), 2), 3)Jurusan Teknik Informatika, Fakultas Teknologi Informasi, Institut Teknologi Adhi Tama \\ Surabaya \\ Jl Arif Rahman Hakim No. 100 Surabaya \\ Email : $\underline{\text { annisaaindrawanti@gmail.com }}{ }^{l)}$, azmuri@yahoo.com ${ }^{2}$, annangfirdiansyah@gmail.com $^{3)}$
}

\begin{abstract}
Abstrak
E-voting adalah sebuah sistem pemilihan umum (PEMILU) online yang dibangun untuk meminimalisasi biaya dan membuat sistem pemilihan lebih efisien. Data pemilihan merupakan data sensitif yang memerlukan keamanan data. Keamanan data yang dibangun mempertimbangkan parameter confidentiality, integrity and availability (triad CIA). Pada penelitian ini, terdapat dua mekanisme untuk mengamankan data pemilihan, yaitu autentikasi user menggunakan RFID dan kriptografi data pemilihan menggunakan metode RSA. Pada hasil percobaan menunjukkan bahwa semakin panjang bit dari bilangan prima acak p dan q, semakin sulit intruder untuk menemukan kunci publik dan kunci privat dan semakin lama waktu yang dibutuhkan untuk membangkitkan kunci, mengenkripsi dan mendekripsi. Selain itu, tingkat keberhasilan autentikasi user menggunakan RFID sebesar $80 \%$ dan tingkat keberhasilan dari proses enkripsi dan dekripsi sebesar $100 \%$.
\end{abstract}

Kata kunci: RSA, Autentikasi RFID, E-Voting

\begin{abstract}
E-voting is an online voting system built to minimalize cost and more efficient. The data voting needs such a data security. The data security has some parameters that have to be considered, they are confidentiality, integrity and availability (triad CIA). In this research, there are two mechanisms to securing data voting. They are RFID user authentication and data e-voting cryptography using RSA. The experimental result show that longer bit length of random prime number $p$ and q, make more difficult intruder will know the public and private key and more time needed for key generator, encryption and decryption. Besides that, success rate of RFID user authentication is $80 \%$ and success rate of encryption and decryption are the same $100 \%$.
\end{abstract}

Keywords: RSA, RFID Authentication, E-Voting

\section{Pendahuluan}

E-voting merupakan sebuah sistem pemilihan umum (PEMILU) online yang memiliki fungsi yang sama dengan sistem pemilu online. Pada e-voting, semua proses mulai dari pemilihan kandidat hingga perhitungan suara dilakukan oleh komputer [2]. Salah satu permasalahan yang muncul pada sistem pemilu manual adalah kecurangan perhitungan suara untuk memenangkan kandidat tertentu. E-voting dapat mengurangi tingkat kecurangan dari sistem pemilu manual. Secure e-voting pada penelitian ini menggunakan autentikasi RFID untuk memvalidasi user pemilih sebelum melakukan pemilihan. RFID (Radio Frequency Identification) adalah teknologi mengidentifikasi menggunakan RFID tag untuk mengirimkan detail informasi mengenai user pemilih ke RFID reader. Dari RFID tag, identitas user pemilih dapat dibaca [7][9]. Setiap user pemilih hanya dapat memilih satu kali dan dicek menggunakan ID dari RFID. Selain itu, securee-voting ini juga mengimplementasikan kriptografi RSA untuk mengamankan kandidat yang dipilih oleh pemilih dari intruder. Intruder adalah seseorang yang mencoba untuk 
mengambil data kandidat yang dipilih oleh user pemilih. Kekuatan metode RSA terletak pada tingkat kesulitan memfaktorkan sebuah bilangan menjadi bilangan faktor prima. Faktorisasi diperlukan untuk memperoleh kunci privat [1][3].

\section{Dasar teori}

\subsection{Voting}

Voting, berasal dari kata vote yang berarti memilih. Sedangkan yang dimaksud voting disini adalah pemungutan suara yang berarti menggunakan hak pilih untuk memilih kandidat, untuk mendapatkan salah satu kandidat yang akan menjadi pemimpin ataupun ketua yang telah disetujui bersama. Di Indonesia sebagai negara demokrasi dengan menggunakan sistem voting untuk pengambilan keputusan dalam pemilihan wakil-wakil rakyat ataupun kepala daerah. Namun dengan berkembangnya kemajuan teknologi saat ini telah membawa perubahan besar pada manusia, termasuk cara untuk melakukan voting. Maka atas dasar perkembangan teknologi tersebut media elektronik dapat digunakan dalam voting, yang disebut $e$-voting. E-voting adalah kepanjangan dari elektronik-voting yaitu pengambilan keputusan bersama untuk menemukan calon pemimpin ataupun ketua dengan elektronik sebagai medianya[4].

Tujuan dari $e$-voting adalah untuk menjamin kerahasiaan, dan keamanan dalam sistem $e$ voting. Maka unsur-unsur dalam $e$-voting meliputi :

- Eligibility : Hanya calon pemilih yang terdaftar yang dapat mengikuti proses voting.

- Unreusability : Setiap pemilih hanya dapat melakukan satu kali voting.

- Accuracy : Pilihan tidak bisa diubah atau dihapus selama atau setelah pemilihan dan juga tidak bisa ditambahkan setelah proses pemilihan ditutup.

- Vote an Go : Pemilih hanya dapat melakukan pemilihan saja.

- Privacy : Pemilih tidak boleh tahu pilihan orang lain.

- Fairness : Orang lain tidak dapat mengetahui hasilnya sebelum dilakukan proses perhitungan suara[6].

\subsection{Autentikasi RFID}

Radio Frequency Identification atau sering disingkat RFID adalah suatu teknologi identifikasi tanpa kabel otomatis menggunakan tag khusus untuk mengirimkan data kepada RFID reader. Sehingga akan didapatkan data identitas dari seseorang yang hanya memiliki tag tersebut. RFID bekerja tanpa adanya sentuhan seperti barcode atau magneticcard (ATM), melainkan menggunakan frekuensi radio. Prinsip kerjanya adalah ketika reader menangkap gelombang radio, apabila tag RFID berada dalam jangkauan gelombang frekuensi radio tersebut, maka chip yang ada pada tag RFID akan dibangkitkan melalui tegangan terinduktansi dan akan memberikan respon balik, yaitu tag RFID akan mengirimkan nomor unik yang tersimpan didalamnya secara wireless ke reader RFID untuk dibaca. Setelah itu reader akan meneruskan data yang dibaca ke host komputer yang terhubung dengan reader[7].

Sistem RFID terdiri dari empat komponen, diantaranya adalah :

- Tag : Ini adalah device yang menyimpan informasi untuk identifikasi objek. Tag RFID sering juga disebut sebagai transponder.

- Antena : Untuk mentransmisikan sinyal frekuensi radio antara pembaca RFID dengan tag RFID. 
- Pembaca RFID : Adalah device yang kompatibel dengan tag RFID yang akan berkomunikasi secara wireless dengan tag.

- Software Aplikasi : Adalah aplikasi pada sebuah workstation atau PC yang dapat membaca data dari tag melalui pembaca RFID. Baik tag dan pembaca RFID dilengkapi dengan antena sehingga dapat menerima dan memancarkan gelombang elektromagnetik [6].

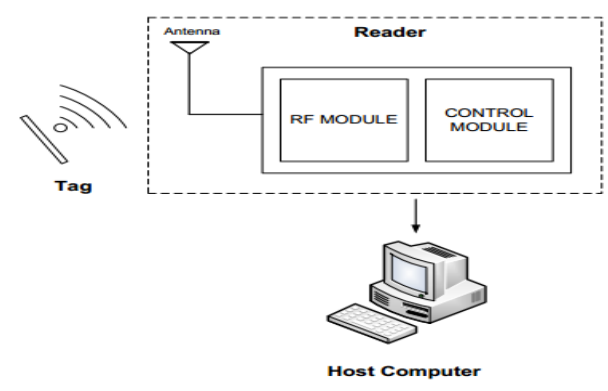

Gambar 8. Skema Mekanisme RFID

\subsection{Metode RSA}

Algoritma kriptografi RSA atau kepanjangan dari Ron Rivest, Adi Shamir and Leonard Adleman, dimana nama nama tersebut juga tokoh yang meneliti algoritma tersebut. Para peneliti ini dari MIT (Massachussets Institute of Technology) pada tahun 1976, dan pertama kali diperkenalkan pada bulan Agustus 1977. Algoritma ini termasuk ke dalam algoritma kriptografi asimetris (Asymetric Cryptography), yaitu algoritma yang menggunakan kunci yang berbeda untuk proses enkripsi dan dekripsi yaitu menggunakan public key dan private key. Public key digunakan untuk mengenkripsi pesan dan didekripsi dengan menggunakan private key. Prosesnya, pengirim (sender) mengenkripsi pesan dengan menggunakan public key milik penerima pesan (receiver) dan hanya penerima pesanlah yang dapat mendekripsi pesan karena hanya penerima yang mengetahui private key nya sendiri [5].

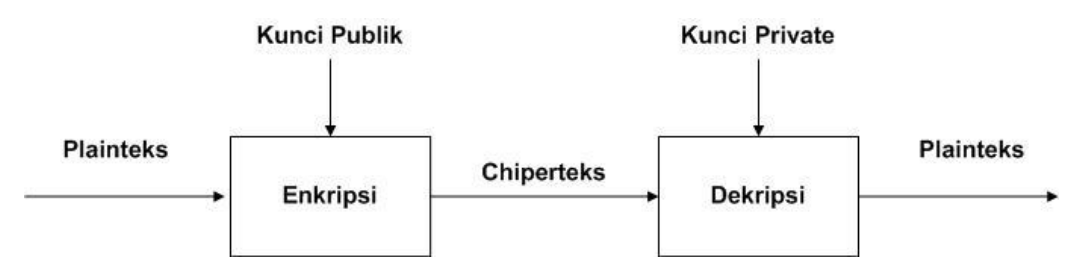

Gambar 9. Skema enkripsi dan dekripsi RSA

Keamanan algoritma RSA terletak pada sulitnya memfaktorkan bilangan yang besar menjadi faktor-faktor prima. Pemfaktoran dilakukan untuk memperoleh private key dan public key. Tingkat keamanan algoritma penyandian RSA sangat bergantung pada ukuran kunci sandi tersebut (dalam bit), karena makin besar ukuran kunci, maka makin besar juga kemungkinan kombinasi kunci yang bisa dijebol dengan metode mengecek kombinasi satu persatu kunci atau lebih dikenal dengan istilah brute force attack. Maka apabila penerapan dalam e-voting, publickey dan private key dibentuk dengan kombinasi kunci algoritma yang unik, otomatis panjang bit akan semakin besar, maka akan membuat penyandian RSA akan semakin kuat meminimalisir terjadinya para hacker untuk membobol algoritma ini[5]. 


\subsubsection{Pembangkitan Kunci}

Algoritma RSA memiliki dua buah kunci yang berbeda untuk proses enkripsi dan dekripsi. Dalam menentukan dua bilangan prima sebagai kunci adalah bilangan prima yang besar, karena pemfaktoran bilangan prima dari dua bilangan prima yang besar sangat sulit, sehingga keamanan pesan lebih terjamin. Pasangan kunci adalah elemen penting dari algortima RSA. Berikut ini adalah langkah-langkah dalam membangkitkan dua kunci algoritma RSA :

Pilih dua bilangan prima sembarang, untuk $p$ dan $q$.

$$
\text { Hitung } n=p . q \text {. }
$$

$$
\text { Hitung } \varnothing(n)=(p-1)(q-1) \text {. }
$$

Pilih kunci publik $e$, yang relatif prima terhadap $\emptyset(n)$. Bangkitkan private key dengan menggunakan rumus (3):

$$
e^{e} \bmod \emptyset(n)=d
$$

Hasil dari algoritma tersebut akan menghasilkan dua kunci, yaitu publickey $(e, n)$ dan private key $(d, n)[5]$.

\subsubsection{Enkripsi RSA}

Enkripsi adalah suatu proses pengamanan data dengan metode tertentu sehingga akan didapatkan suatu data enkripsi berupa chipertext. Dalam RSA, data yang akan dienkripsi disebut plaintext, dan data setelah dienkripsi disebut chipertext. Dengan $m$ adalah plaintext dan $C$ adalah proses enkripsi untuk menghasilkan chipertext. Dengan adanya public key $(e, n)$ maka proses enkripsi dengan rumus (4):

$$
c=m^{e} \bmod n .
$$

\subsubsection{Dekripsi RSA}

Dekripsi adalah suatu proses untuk mendapatkan nilai suatu plaintext seperti semula dari data chipertext yang ada. Chipertext yang diperoleh setelah proses enkripsi RSA dan didapat private key $(d, n)$, maka akan didekripsi dengan rumus (5):

$$
m=c^{d} \bmod n
$$

\section{Metodologi Penelitian}

\subsection{E-Voting}

E-voting adalah sebuah sistem pemilihan umum (PEMILU) online. PEMILU dilakukan mulai dari pemilihan kandidat hingga perhitungan suara[2]. Setiap tahapan pemilu akan diproses menggunakan komputer untuk meminimalisasi intruder dan human error. Data dari e-voting merupakan data sensitif yang memerlukan triad security, yaitu confidentiality, integrity dan availability[8]. Pada e-voting ini, identitas seorang user diautentikasi menggunakan teknologi RFID. Teknologi RFID terdiri dari RFID tag dan RFID reader. Setiap user memiliki satu RFID tag yang akan menyimpan detail informasi dari user, seperti ID user, nama dan alamat. Kemudian, setiap user memilih satu kandidat dan sistem e-voting akan mengenkripsi data kandidat yang dipilih user menggunakan metode RSA serta mengirimkannya ke server. Setelah tiba di server, data akan didekripsi menggunakan metode RSA. Diagram sistem e-voting secara keseluruhan ditunjukkan pada Gambar 3. 


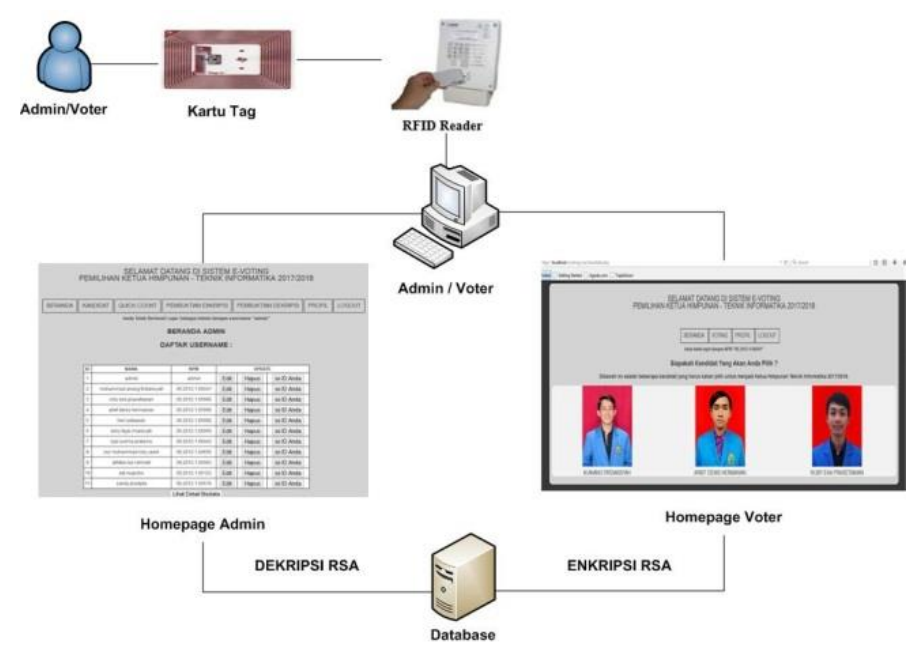

Gambar 10. Sistem e-voting online

Setiap pemilih yang memiliki RFID tag mendekatkan RFID tag yang dimiliki kepada RFID reader untuk membaca detail informasi identitas dari pemilih. Setelah RFID reader memperoleh detail informasi identitas pemilih, sistem e-voting akan menampilkan homepage. Kemudian, user dapat memilih salah satu dari kandidat yang ada.RSA mengenkripsi ID dari RFID tag dan kandidat yang dipilih menggunakan kunci publik RSA dan mengirimkannya ke server. Server akan mendapatkan ID dari RFID dan kandidat yang dipilih user yang telah terenkripsi. Kemudian, sistem akan mendekripsi data terenkripsi tersebut menggunakan kunci privat dari metode RSA.

\subsection{Autentikasi RFID}

Autentikasi adalah proses verifikasi untuk mengetahui true user dan mencegah fake user. Pada proses autentikasi ini, e-voting menggunakan teknologi RFID yang terdiri dari RFID tag dan RFID reader. Setiap komputer pada sistem e-voting akan di-embed oleh sebuah RFID reader. Proses pemilihan akan dimulai dengan autentikasi RFID. Pemilih akan mendekatkan RFID tag ke RFID reader dan gelombang frekuensi radio akan mengirimkan ID dari RFID tag pemilih ke RFID reader. Sistem e-voting akan membaca semua detail informasi mengenai user pemilih. RFID reader dikoneksikan melalui RS232 ke kabel serial USB.

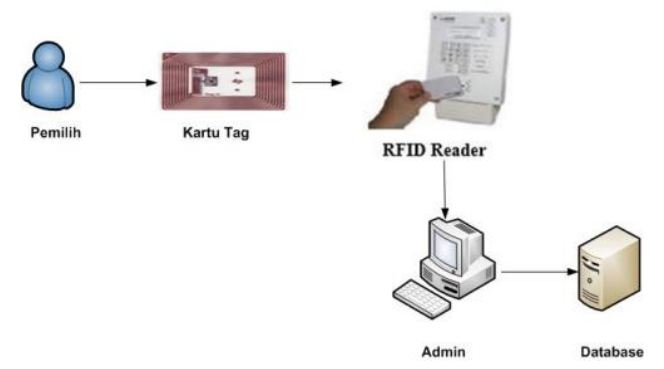

Gambar 11. Autentikasi RFID

\subsection{Metode RSA}

\subsubsection{Pembangkitan Kunci}

Metode RSA memiliki 2 kunci yang berbeda untuk proses enkripsi dan dekripsi[10]. Metode ini menggunakan bilangan prima untuk menentukan kunci publik dan kunci privat karena tingkat kesulitan yang tinggi dalam memfaktorkan bilangan prima yang besar. Hal ini 
dimanfaatkan oleh RSA dalam menjaga confidentiality dari pesan.Berikut ini adalah langkahlangkah pembangkitan kunci :

- Memilih bilangan prima acak $p$ and $q$

- Menghitung $n=p . q$

- Menghitung $\emptyset(n)=(p-1)(q-1)$

- Memilih kunci public $e$ yang relatif prima terhadap $\emptyset(n)$.

- Menghitung kunci privat $d$ dengan rumus $e . d \equiv 1(\bmod \emptyset(n))$, yang ekivalen terhadap $e . d=1+k \emptyset(n)$, sehingga $d=\frac{1+k \emptyset(n)}{e}$.

Proses pembangkitan kunci menghasilkan output kunci publik $(e, n)$ dan kunci privat $(d, n)$. kunci publik $(e, n)$ bersifat tidak rahasia, tetapi kunci privat $(d, n)$ bersifat rahasia.

\subsubsection{Enkripsi RSA}

Setelah proses pembangkitan kunci menghasilkan output kunci publik $(e, n)$ dan kunci privat $(d, n)$, sistem mengenkripsi ID dari RFID dan kandidat terpilih. Berikut langkah-langkah enkripsi RSA :

- Masukkan berupa plaintext $\mathrm{m}$

- Membagi $m$ ke dalam beberapa blok $m_{1}, m_{2}, m_{3}, \ldots \ldots, m_{i}$

- Setiap blok $m_{i}$ merepresentasikan sebuah karakter

- Mencari nilai ASCII dari setiap blok $m_{i}$

- Mengenkripsi setiap blok $m_{i}$ menjadi chipertext $c_{i}$ dengan rumus (9) :

$c_{i}=m_{i}^{e} \bmod n$

Enkripsi RSA akan menghasilkan chipper text $\mathrm{c}_{1}, \mathrm{c}_{2}, \mathrm{c}_{3}, \ldots, \mathrm{c}_{\mathrm{i}}$

\subsubsection{Dekripsi RSA}

Setelah enkripsi RSA menghasilkan chipertext dari ID RFID dan kandidat yang dipilih, chipertext akan dikirimkan ke server. Chipertext didekripsi menjadi plaintext dengan langkahlangkah berikut :

- Dekripsi setiap blok dari chipertext menggunakan rumus $m_{i}=c_{i}^{d} \bmod n$

- Hasil dekripsi menghasilkan nilai ASCII setiap blok

- Konversi nilai ASCII ke plaintext $m$

- Sistem akan menerima plaintext untuk menghitung jumlah pemilih dari setiap kandidat

\section{Pengujian dan Pembahasan}

Pada subbab ini akan dijelaskan mengenai pengujian fungsional dan pengujian performa. Pengujian fungsional dilakukan untuk melihat tingkat keberhasilan autentikasi RFID, proses enkripsi dan dekripsi RSA. Sedangkan pengujian performa dilakukan untuk melihat pengaruh panjang bit dari bilangan prima acak $p$ dan $q$ terhadap waktu komputasi proses pembangkitan kunci, enkripsi RSA dan dekripsi RSA yang menandai tingkat kesulitan intruder dalam memfaktorkan bilangan prima acak $p$ dan $q$.

\subsection{Pengujian Fungsionalitas}

Pengujian ini dilakukan untuk melihat tingkat keberhasilan sistem meliputi autentikasi RFID, enkripsi dan dekripsi RSA. Skenario pengujian yang dilakukan adalah melakukan proses 
autentikasi RFID, enkripsi dan dekripsi RSA sebanyak 10 kali dan melihat keberhasilan setiap proses. Hasil pengujian fungsionalitas ditunjukkan pada Tabel 1.

Tabel 1. Hasil pengujian fungsionalitas autentikasi RFID, enkripsi dan dekripsi

\begin{tabular}{|l|l|l|l|l|l|}
\hline No. & \multicolumn{1}{|c|}{$\begin{array}{c}\text { Jenis pengujian } \\
\text { fungsionalitas }\end{array}$} & $\begin{array}{c}\text { Tingkat } \\
\text { keberhasilan } \\
\text { (kali) }\end{array}$ & $\begin{array}{c}\text { Tingkat } \\
\text { kegagalan } \\
\text { (kali) }\end{array}$ & Jumlah & Tingkat keberhasilan \\
\hline 1 & Autentikasi RFID & 8 & 2 & 10 & $(8 / 10) \times 100 \%=80 \%$ \\
\hline 2 & Enkripsi & 10 & 0 & 10 & $(10 / 10) \times 100 \%=100 \%$ \\
\hline 3 & Dekripsi & 10 & 0 & 10 & $(10 / 10) \times 100 \%=100 \%$ \\
\hline
\end{tabular}

Dari Tabel 1 ditunjukkan bahwa dari 10 kali percobaan, tingkat keberhasilan proses autentikasi RFID sebesar 80\%, tingkat keberhasilan proses enkripsi sebesar $100 \%$ dan tingkat keberhasilan dekripsi sebesar $100 \%$.

\subsection{Pengujian Performa}

Pengujian performa dilakukan untuk melihat pengaruh variasi panjang bit terhadap waktu komputasi dari pembangkitan kunci, enkripsi dan dekripsi. Skenario pengujian yang dilakukan adalah memvariasikan panjang bit dari bilangan acak prima dengan variasi panjang bit 8,16, 64, 100, 200, 300 dan 400 dan melihat pengaruh variasi panjang bit terhadap waktu komputasi pembangkitan kunci, enkripsi dan dekripsi. Hasil pengujian performa ditunjukkan pada Tabel 2.

Tabel 2. Hasil pengujian performa pengaruh variasi panjang bit bilangan prima acak $\mathrm{p}$ dan $\mathrm{q}$ terhadap waktu komputasi pembangkitan kunci, enkripsi dan dekripsi

\begin{tabular}{|c|c|c|c|}
\hline \multirow{2}{*}{$\begin{array}{c}\text { Skenario pengujian: variasi } 7 \text { jenis panjang bit yang berbeda dari bilangan } \\
\text { prima acak } p \text { dan } q \text { dan melihat pengaruhnya terhadap waktu komputasi } \\
\text { pembangkitan kunci (PK), enkripsi (E) dan dekripsi (D) }\end{array}$} \\
\hline $\begin{array}{c}\text { Panjang bit bilangan } \\
\text { prima acak } \boldsymbol{p} \text { dan } \boldsymbol{q}\end{array}$ & \multicolumn{3}{|c|}{ Waktu komputasi (ms) } \\
\cline { 2 - 4 } & PK & E & D \\
\hline 8 & $766.0 \mathrm{~ms}$ & $1 \mathrm{~ms}$ & $3 \mathrm{~ms}$ \\
\hline 16 & $3020 \mathrm{~ms}$ & $1 \mathrm{~ms}$ & $4 \mathrm{~ms}$ \\
\hline 64 & $4690 \mathrm{~ms}$ & $6 \mathrm{~ms}$ & $10 \mathrm{~ms}$ \\
\hline 100 & $4806 \mathrm{~ms}$ & $6 \mathrm{~ms}$ & $18 \mathrm{~ms}$ \\
\hline 200 & $6671 \mathrm{~ms}$ & $15 \mathrm{~ms}$ & $106 \mathrm{~ms}$ \\
\hline 300 & $7467 \mathrm{~ms}$ & $63 \mathrm{~ms}$ & $155 \mathrm{~ms}$ \\
\hline 400 & $11199 \mathrm{~ms}$ & $217 \mathrm{~ms}$ & $519 \mathrm{~ms}$ \\
\hline
\end{tabular}

Pada Tabel 2 ditunjukkan bahwa semakin panjang bit dari bilangan prima acak $p$ dan $q$, maka semakin lama waktu yang dibutuhkan untuk melakukan proses pembangkitan kunci, enkripsi dan dekripsi dan hal ini semakin menyulitkan intruder untuk memfaktorkan bilangan prima acak $p$ dan $q$. Hal ini juga ditunjukkan dalam bentuk grafik pada Gambar 5, Gambar 6 dan Gambar 7. 


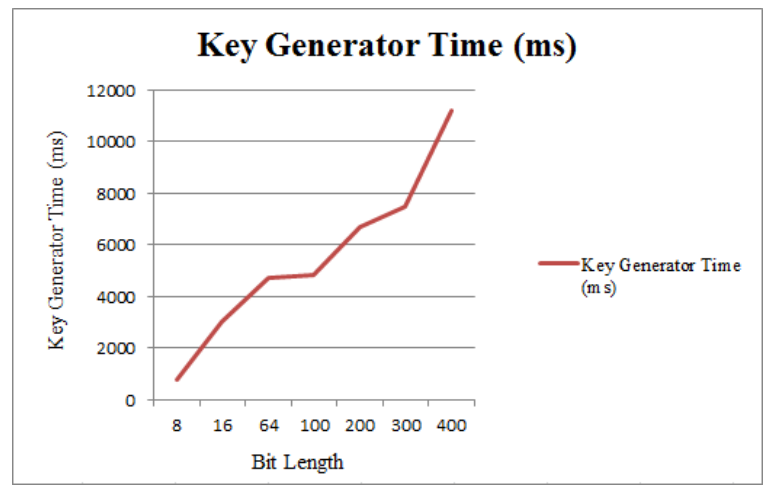

Gambar 12. Pengaruh panjang bit bilangan prima acak $p$ dan $q$ terhadap waktu komputasi pembangkitan kunci

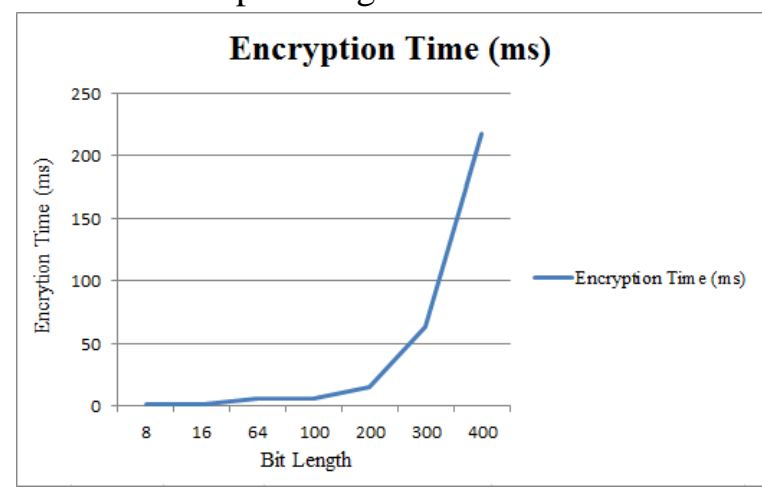

Gambar 13. Pengaruh panjang bit bilangan prima acak p dan q terhadap waktu komputasi enkripsi

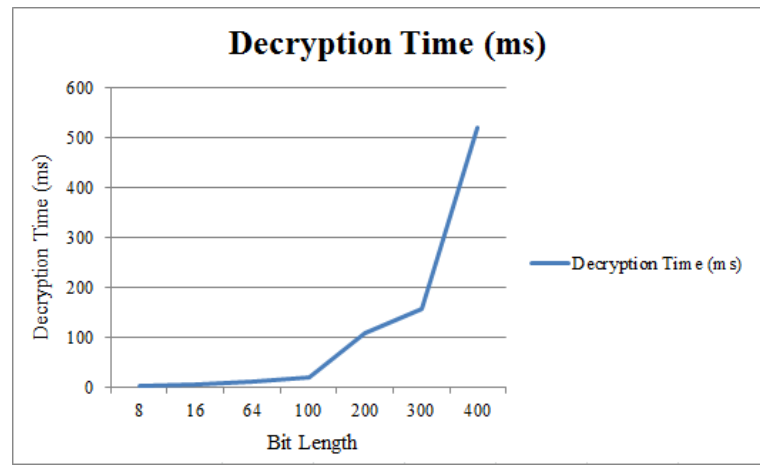

Gambar 14. Pengaruh panjang bit bilangan prima acak p dan q terhadap waktu komputasi dekripsi

\section{Kesimpulan}

Dari percobaan secure e-voting yang dilakukan pada penelitian ini dapat disimpulkan bahwa semakin panjang bit bilangan prima acak $\mathrm{p}$ dan q yang diberikan, maka semakin lama waktu komputasi yang dibutuhkan dan hal ini semakin menyulitkan intruder untuk memfaktorkan bilangan acak prima $\mathrm{p}$ dan $\mathrm{q}$. sistem secure e-voting ini juga memiliki tingkat keberhasilan dalam autentikasi user menggunakan RFID sebesar $80 \%$, tingkat keberhasilan enkripsi sebesar $100 \%$ dan tingkat keberhasilan dekripsi sebesar $100 \%$. 


\section{Daftar Pustaka}

[1] Gotimukul V., Sunkara V.G, Mrudula M., Sindhu C. Application of Session Login and One Time Password in Fund Transfer System using RSA Algorithm. International Conference on Electronics, Communication and Aerospace Technology (ICECA). 2017.

[2] Nobert K., Melaine V., Nadja B.B., Norbert K., Olivier P., Carsten S. "Electronic Voting". Second International Joint Conference Bregenz, Austria, Switzerland: Springer International Publishing AG. October 24-27, 2017.

[3] Fausto Meneses, et. al, Jenny Tores, Alba Miranda, et. al. "RSA Encryption Algorithm Optimization to Improve Performance and Security Level of Network Messages". International Journal of Computer Science and Network Security Vol. 16 No. 8, pp 5562, 2016.

[4] Neyman, Shelvie Nidya. Isnaini, Muhammad Fikri. Nurdiati, Sri. Penerapan Sistem Evoting pada Pemilihan Kepala Daerah di Indonesia (The Application of E-voting Systems in the Local Elections in Indonesia). Departemen Ilmu Komputer FMIPA IPB. Bogor. Jurnal Sains Terapan Edisi III Vol. 3, 2013.

[5] R, Dicky Wizanajani. "Perbandingan Algoritma Berbasis Elliptic Curve Cryptography Dengan RSA Dan DSA Pada Tanda tangan Digital”. Institut Teknologi Bandung. Bandung. 2006.

[6] Afrin, Tanzila. Satao, K.J. "E-Voting System for on Duty Person Using RSA Algorithm with Kerberos Concept". International Journal of Advanced Research in Computer Engineering \& Technology (IJARCET), Vol, 2, No.7 , pp 2258-2261, 2013

[7] Saad, Amna. Roseli, Mohd Izzat Mohamat, Zullkaeply, Muhammad Saufi. A Smart EVoting System Using RFID Authentification Method For A Campus Electoral. Malaysian Institute of Information Technology. Kuala Lumpur. 2013.

[8] Hutagalung, Muhammad Kifli. Perancangan Perangkat E-Voting Berbasis E-KTP. STMIK Triguna Dharma. Medan. 2012.

[9] Syed Ahson, Mohammad Ilyas. RFID Handbook: Application, Technology, Security and Privacy. United States of America: CRC Press Taylor \& Francis Group. 2008.

[10] Rinaldi Munir. "Algoritma RSA dan El Gamal”. Institut Teknologi Bandung. Bandung: Makalah IF5054 Kriptografi. 2004. 